\title{
REFORMA DO CÓDIGO FLORESTAL E APLICAÇÃO PRÁTICA NO ÂMBITO DA BACIA HIDROGRÁFICA DO RIO ARARANGUÁ - SC
}

\author{
REFORM OF FOREST CODE AND PRACTICAL APPLICATION UNDER \\ THE BASIN OF RIVER ARARANGUÁ - SC
}

\author{
Michele Pereira da Silva ${ }^{1}$ \\ Yasmine de Moura da Cunha ${ }^{2}$ \\ Silvio Krinski ${ }^{3}$
}

\begin{abstract}
Resumo
As diretrizes do direito ambiental ampliam e auxiliam no desenvolvimento de atividades de fiscalização e manutenção do ambiente ecologicamente equilibrado. O Código Florestal Brasileiro estabelece normais gerais referente a proteção e preservação da fauna brasileira, na manutenção de espécies e prevê instrumentos econômicos e financeiros para alcançar seus objetivos e possibilita o direcionamento do desenvolvimento socioeconômico, tendo em vista a execução de atividades de diversos setores. Considerando o território dividido em bacias hidrográficas e a interação dos setores com o ecossistema, surgiu a necessidade de buscar a compreensão das principais alterações nas normas jurídicas relacionadas à questão ambiental. A pesquisa realizada teve como objetivo elucidar sobre as principais alterações na lei que institui o Código Florestal e a sua aplicação em área de bacia hidrográfica, tendo como o objetivo o desenvolvimento sustentável. Foi realizada uma análise comparativa das leis regulamentadas e suas medidas provisórias, e aplicadas em território de bacia hidrográfica para verificar a real possibilidade de aplicação do Código Florestal.
\end{abstract}

Palavras-chave: bacia hidrográfica, código florestal, desenvolvimento sustentável.

\begin{abstract}
The guidelines of environmental law and extend help in the development of activities of inspection and maintenance of ecologically balanced environment. The Brazilian Forest Code establishes general standard regarding the protection and preservation of Brazilian fauna in maintaining species and provides economic and financial instruments to achieve its objectives and enables the direction of socio-economic development, with a view to implementation of various sectors activities. Considering the territory divided into watersheds and the interaction of the sectors with the ecosystem, the need to seek the understanding of the main changes in the legal regulations related to environmental issues. The research aimed to elucidate the main changes in the law establishing the Forest Code and its application in river basin area, and as the goal of sustainable development. a comparative analysis of regulated laws was conducted and its

\footnotetext{
${ }^{1}$ Engenheira Ambiental, Especialista em Direito Ambiental. engenheiramicheleps@ gmail.com

${ }^{2}$ Geóloga, Mestre em Geografia. Professora na Universidade do Extremo Sul Catarinense - UNESC. ymc@unesc.net

3 Engenheiro Agrônomo, Mestre em Produção Vegetal. Professor Universidade Federal do Paraná UFPR.skrinski@hotmail.com
} 
provisional measures, and applied in the territory of river basin to check the real possibility of applying the Forest Code.

Keywords: watershed, forest code, sustainable development.

\section{INTRODUÇÃO}

$\mathrm{Na}$ atualidade, é crescente a preocupação com a preservação dos recursos naturais. A cada dia, ações voltadas à realização de projetos, programas e atividades ambientais estão mais integradas à vida da comunidade em âmbito mundial.

A Constituição Federal de 1988, em seu Art. 225 definiu a necessidade de proteção e preservação do meio ambiente. Após a Constituição Federal, foram instituídas leis que complementaram a proteção dos recursos hídricos, e, de forma detalhada, forneceram subsídios para a aplicação de cobrança para a sua preservação.

No ano de 1997 , foi promulgada no Brasil a Lei $n^{\circ} 9.433$, que instituiu a criação de Comitês de Bacias Hidrográficas. Na referida Lei está contemplado que as bacias hidrográficas são unidades de planejamento territoriais (BRASIL, 1997). Deste modo, a organização da gestão dos bens públicos naturais, renováveis ou não, passa a ser planejada por um colegiado instituído para este fim.

O objetivo primordial deste artigo é analisar as principais alterações no Código Florestal Brasileiro de 1965 inseridas pela Lei $\mathrm{n}^{\circ}$ 12.651/2012, e os principais impactos que estas alterações podem ocasionar em área de bacia hidrográfica.

A ânsia por obter resultados significativos com relação à execução das diretrizes nacionais impulsiona o desenvolvimento de pesquisas acerca da aplicação da nova Lei $n^{\circ} 12.651 / 12$ em detrimento das alterações da Lei $n^{\circ} 4771 / 65$, buscando ampliar os conhecimentos das principais alterações no sistema de Gestão de Recursos Hídricos, Comitês de Bacias Hidrográficas, e, ainda, na proteção dos recursos naturais existentes.

Rodrigues (2013) apresenta as diversas discussões relativas ao processo de atualização do Código Florestal, relacionando as alterações realizadas no código aprovado em 2012, com o trabalho desenvolvido pela bancada ruralista, com intuito de beneficiar o setor agrícola e os agricultores. 
O termo área consolidada apresentada na nova legislação tem como base fundamentar e legalizar o processo de supressão de vegetação que foi realizado anterior ao ano de 2008. Para Rodrigues (2013) esta data culminou com a promulgação do Decreto $\mathrm{n}^{\circ}$ 6514/08, e combinado com outros instrumentos legais já criados, foram direcionados para o resolver o sistema de multas estipulados pela Lei 9605/98, e minimizar os custos de multas ambientais e criou-se um novo regime político diferenciado para áreas de preservação permanente e reserva legal. Dividindo entre APP e reserva legal consolidadas e áreas não consolidadas, sendo estes dois regimes divergentes, um para os infratores que não respeitaram a legislação, e outro para os não infratores que respeitaram as leis. Contudo Rodrigues (2013), frisa que o legislador do novo código florestal pensou em beneficiar os primeiros.

Carvalho (2014) cita que o código florestal de 2012, apresentou o pior cenário possível, para o processo de preservação ambiental, desprotegendo o ambiente e não solucionando o problema relacionado a falta de governança ambiental, dividindo o ônus da recuperação ambiental a diversos setores de forma arbitrária, atingindo os pequenos produtores agrários, os produtores familiares, os não familiares, quem cumpriu e quem descumpriu o código de 1965. E ainda, proporciona tratamento igualitários entre os produtores familiares e produtores não familiares.

Inerente aos poderes econômico e político, o domínio da legislação proporciona aos grandes latifundiários a proteção de seus bens, porém, pequenos agricultores e agricultores familiares possuem dificuldade de compreender as novas práticas a serem adotadas. Deste modo, torna-se necessário realizar um levantamento das principais mudanças do Código Florestal, e, posteriormente, aplicar as novas regras no âmbito da bacia hidrográfica do rio Araranguá, de forma a elucidar estas questões os produtores rurais e usuários de água na bacia.

É imprescindível realizar a identificação das principais alterações no Código Florestal e a aplicação destas regras no âmbito de bacia hidrográfica, em virtude da necessidade de utilização por diversos setores, de forma a elucidar a população e também fortalecer o senso de proteção dos recursos naturais existentes, ampliando o conhecimento da coletividade acerca das novas regras do direito ambiental, para um desenvolvimento sustentável. 


\section{METODOLOGIA}

A classificação dos tipos de pesquisa inicialmente é dividida em dois grandes grupos: qualitativas e experimentais. O método de pesquisa experimental é baseado na comprovação de fatos, por meio de experiências e análises, seguindo as regras e controles coerentes à utilização. $\mathrm{O}$ método qualitativo está relacionado ao conhecimento das características e na compreensão de um determinado grupo social (PHILIPPI JR, 2005).

Após a divisão inicial, a pesquisa é subdividida em: teórica ou fundamental, aplicada, descritiva, analítica e nomotética. Estas são análises de dados teóricos, aplicações dos conhecimentos adquiridos, a busca por novas descrições do tema abordado, uma análise de dados, e, a relação de leis que determinam a interação de fenômenos ocorridos com a realidade, respectivamente (PHILIPPI JR, 2005).

O artigo foi elaborado por meio de análise de dados teóricos, definindo a pesquisa como teórica. Inicialmente foi elaborado um levantamento de referencial teórico de bacia hidrográfica, gestão de recursos hídricos e do Código Florestal. Na sequencia foi realizada a comparação da atualização do Código Florestal instituído pela Lei $n^{\circ} 12.651 / 2012$ e do Código Florestal instituído pela Lei no 4.771/65.

\section{Caracterização da Área de Estudo}

A Bacia é formada por 16 municípios que têm os seus territórios inseridos total ou parcialmente na bacia. E pode-se observar que, dos 16 municípios que a integram, dez (Ermo, Forquilhinha, Maracajá, Meleiro, Morro Grande, Nova Veneza, Siderópolis, Timbé do Sul, Treviso e Turvo) estão totalmente inseridos na bacia. Os municípios de Araranguá, Balneário Rincão, Criciúma, Içara e Jacinto Machado, possuem mais de $50 \%$ do território inserido na bacia, e Balneário Arroio do Silva possui sua sede na área da bacia (Santa Catarina, 2015)

A população total da bacia hidrográfica, considerando-se o total da população dos municípios, corresponde a aproximadamente 420.500 habitantes, o que significa 6,7\% da população do Estado de Santa Catarina, que é de 6,25 milhões de habitantes 
(IBGE, 2010). A área da Bacia Hidrográfica do Rio Araranguá possui $3.089 \mathrm{~km}^{2}$, o que corresponde a 3,07\% do território catarinense.

\section{DESENVOLVIMENTO SUSTENTÁVEL}

A essência do desenvolvimento sustentável é baseada num processo de mudança no padrão de exploração dos recursos naturais no qual a exploração desses recursos, o direcionamento dos investimentos, a orientação do desenvolvimento tecnológico e a mudança institucional estão em harmonia e reforçam o atual e futuro potencial para satisfazer as aspirações e necessidades humanas (COMISSÃO MUNDIAL ENTRE MEIO AMBIENTE E DESENVOLVIMENTO, 1991).

O melhor conceito é apresentado pela Comissão Mundial Entre Meio Ambiente e Desenvolvimento (1991), que define como desenvolvimento sustentável o “desenvolvimento capaz de suprir as necessidades da geração atual, sem comprometer a capacidade de atender as necessidades das futuras gerações. " É o desenvolvimento que não esgota os recursos para o futuro, e adapta a utilização atual do consumo para que outras gerações possam ter acesso aos recursos.

No direito ambiental brasileiro, para o "desenvolvimento sustentável" não existem normas que apresentem explicitamente condutas para a sociedade ou poder público, considerando que nenhum instrumento legal definiu o conceito de desenvolvimento de forma a definir e estabelecer requisitos de aplicação (MILARÉ, 2013).

\section{GESTÃO DE RECURSOS HÍDRICOS}

Na Constituição Federal de 1988, o Art. 225 rege que todos têm direito ao meio ambiente ecologicamente equilibrado, bem de uso comum do povo e essencial à sadia qualidade de vida, impondo ao poder público e à coletividade o dever de defendê-lo e preservá-lo para as presentes e futuras gerações.

Considerando a gestão de recursos hídricos no Brasil, é necessário ter ciência de que o processo de mobilização social e preocupação com esse recurso foi instituído legalmente pela Lei $n^{\circ} 9.433$ de 1997, que institui a Política Nacional de Recursos 
Hídricos, criando o Sistema Nacional de Gerenciamento de Recursos Hídricos e define a bacia hidrográfica como unidade de planejamento. O Art. $2^{\circ}$ da referida Lei apresenta em seu caput que é objetivo da Política Nacional de Recursos Hídricos, "assegurar à atual e às futuras gerações a necessária disponibilidade de água, em padrões de qualidade adequados aos respectivos usos", sendo que cabe ao comitê de gerenciamento de bacia hidrográfica a gestão dos recursos hídricos de forma imparcial e igualitária, de forma a definir os usos prioritários, e as reais necessidades dos usuários (BRASIL, 1997).

A definição de bacia hidrográfica é baseada no reconhecimento dos divisores de água, sendo estes, linhas imaginárias nas áreas altas dos terrenos. Esses divisores estabelecem a delimitação das bacias vizinhas e permitem a formação de uma rede de drenagem, escoando as águas superficiais desde as nascentes, pelos rios principais até a foz (ADAMI; CUNHA; FRANK, 2010).

Cada bacia hidrográfica possui um relevo diferenciado, proveniente do sistema de formação geológico, do tipo de solo, vento, erosão entre outros sistemas (ADAMI; CUNHA; FRANK, 2010). A Lei no 9433 de 1997, define em seu Art. 1º, inciso V e VI, a área de bacia hidrográfica como unidade de gerenciamento de água. Ressaltando que esse sistema é composto por um rio principal e seus afluentes.

É necessário compreender, ainda, que as alterações ocasionadas na área da bacia influenciam diretamente a dinâmica dos rios, lagos, e também das cidades, alterando o fluxo de energia, material dissolvido e sedimento. A retirada de mata ciliar, desmatamento de nascentes e impermeabilização do solo influenciam na infiltração da água e ampliam o escoamento superficial de água para os rios (MENDONÇA; SANTOS, 2006).

O gerenciamento destes recursos hídricos é desenvolvido por meio da elaboração e aplicação do plano de bacia, instrumento da Política Nacional de Recursos Hídricos que norteia o desenvolvimento da região da bacia (BRASIL, 1997).

\section{CÓDIGO FLORESTAL}

Moreau (1974, citado por MAGALHÃES, 2001) apresenta a importância da manutenção da vegetação para a preservação da biodiversidade, conservação do solo, 
influências no clima, proteção do ar e a regularização do regime das águas. Neste sentido, está o relevante papel dos três domínios - União, Estados e Municípios -, a proteção dos espaços florestados e o controle da exploração.

A aplicação do Código Florestal é basicamente para propriedades privadas, com a finalidade de recuperar áreas vegetais, por meio da manutenção de áreas de preservação permanente (APP) e reserva legal (RL). Estes são espaços destinados à manutenção dos recursos naturais, como a proteção dos recursos hídricos, manutenção do solo e proteção da biodiversidade (SPAROVEK, 2011).

As alterações do Código Florestal podem ser compreendidas como um marco regulatório ao setor produtivo e ambiental, e permitirá novos desafios a serem enfrentados. A aplicação do novo código, possibilitará o afloramento de novas discussões e a necessidade de adaptação prática à nova lei (KRINSKI, 2012).

A nova legislação tem como resultado final a publicação oficial de três instrumentos de gestão, sendo eles a Lei $n^{\circ} 12.651 / 2012$, que dispõe sobre as regras de proteção da vegetação nativa; a Lei $n^{\circ}$ 12.727/2012, altera a Lei $n^{\circ} 12.651$, de 25 de maio de 2012, que dispõe sobre a proteção da vegetação nativa, e o Decreto $\mathrm{n}^{\mathbf{o}}$ 7.830/2012, que regulamenta o Sistema de Cadastro Ambiental Rural e estabelece normas de caráter geral aos Programas de Regularização Ambiental (KRINSKI, 2012).

\section{Definições do Código Florestal de 1965}

A Lei $n^{\circ}$ 4.771/1965, já revogada, apresenta as regulamentações acerca da utilização e critérios para extração, ocupação das áreas de preservação permanente e reserva legal, bem como delimita em seus artigos de que essas áreas são um bem de utilidade pública e de interesse da coletividade, conforme quadro 01.

Quadro 01 - Definições instituídas pela Lei no 4.771 de 1965.

\begin{tabular}{|c|c|c|}
\hline Tipologia & Descrição & Detalhamento \\
\hline \multirow{3}{*}{$\begin{array}{c}\text { Área de } \\
\text { Preservação } \\
\text { Permanente } \\
\text { - APP - } \\
\text { Art. 2 }\end{array}$} & \multirow{3}{*}{$\begin{array}{l}\text { A) Ao longo dos rios ou de qualquer curso } \\
\text { d'água desde o seu nível mais alto em faixa } \\
\text { marginal, cuja largura mínima será: }\end{array}$} & $\begin{array}{l}30 \text { metros para cursos d'água } \\
\text { de menos de } 10 \text { metros de } \\
\text { largura; }\end{array}$ \\
\hline & & $\begin{array}{l}50 \text { metros para cursos d'água } \\
\text { que tenham de } 10 \text { a } 50 \text { metros; }\end{array}$ \\
\hline & & $\begin{array}{l}100 \text { metros para cursos d'água } \\
\text { que tenham de } 50 \text { a } 200 \\
\text { metros; }\end{array}$ \\
\hline
\end{tabular}




\begin{tabular}{|c|c|c|}
\hline & & $\begin{array}{l}200 \text { metros para cursos d'água } \\
\text { que tenham de } 200 \text { a } 600 \\
\text { metros. }\end{array}$ \\
\hline & $\begin{array}{l}\text { B) Ao redor das lagoas, lagos ou reservatórios } \\
\text { d'água naturais ou artificiais. }\end{array}$ & \\
\hline & $\begin{array}{l}\text { C) Nascentes, ainda que intermitentes, e nos } \\
\text { chamados "olhos d'água", qualquer que seja a } \\
\text { situação topográfica. }\end{array}$ & $\begin{array}{l}\text { Raio mínimo de } 50 \text { metros de } \\
\text { largura. }\end{array}$ \\
\hline & $\begin{array}{l}\text { D) Topos de morros, montes, montanhas e } \\
\text { serras; }\end{array}$ & \\
\hline & E) Encostas ou partes dessas. & $\begin{array}{l}\text { Declividade superior a } 45^{\circ} \text {, } \\
\text { equivalente a } 100 \% \text { de maior } \\
\text { declividade. }\end{array}$ \\
\hline & $\begin{array}{l}\text { F) Restingas, como fixadoras de dunas ou } \\
\text { estabilizadoras de mangues; }\end{array}$ & \\
\hline & G) Bordas dos tabuleiros ou chapadas. & $\begin{array}{l}\text { A partir da linha de ruptura do } \\
\text { relevo, em faixa nunca inferior } \\
\text { a } 100 \text { metros em projeções } \\
\text { horizontais. }\end{array}$ \\
\hline & $\begin{array}{l}\text { H) Altitude superior a } 1.800 \text { mil metros, } \\
\text { qualquer que seja a vegetação. }\end{array}$ & \\
\hline & I) Áreas metropolitanas definidas por Lei. & \\
\hline & $\begin{array}{l}\text { I) Área de floresta localizada na Amazônia } \\
\text { legal }\end{array}$ & $80 \%$ da propriedade rural \\
\hline $\begin{array}{l}\text { Reserva } \\
\text { legal }-\mathrm{RL}-\end{array}$ & II) Área de cerrado na Amazônia legal. & $\begin{array}{l}35 \% \text { da propriedade, sendo no } \\
\text { mínimo } 20 \% \text { na propriedade e } \\
15 \% \text { em compensação em } \\
\text { outra área, desde que na } \\
\text { mesma microbacia. }\end{array}$ \\
\hline & $\begin{array}{l}\text { III) em área de floresta ou outras formas de } \\
\text { vegetação nativa localizada nas demais regiões } \\
\text { do país; }\end{array}$ & $20 \%$ da propriedade rural \\
\hline & $\begin{array}{l}\text { IV) em área de campos gerais localizada em } \\
\text { qualquer região do país }\end{array}$ & $20 \%$ da propriedade rural \\
\hline $\begin{array}{l}\text { Pequena } \\
\text { Propriedade. } \\
\text { Art. } 1^{\circ} \\
\text { Inciso I }\end{array}$ & $\begin{array}{l}\text { Localizada nos Estados do Acre, Pará, } \\
\text { Amazonas, Roraima, Rondônia, Amapá e Mato } \\
\text { Grosso e nas regiões situadas ao norte do } \\
\text { paralelo } 13^{\circ} \mathrm{S} \text {, dos Estados de Tocantins e } \\
\text { Goiás, e ao oeste do meridiano de } 44^{\circ} \mathrm{W} \text {, do } \\
\text { Estado do Maranhão ou no Pantanal mato- } \\
\text { grossense ou sul-mato-grossense. }\end{array}$ & Cento e cinquenta hectares \\
\hline & $\begin{array}{l}\text { Localizada no polígono das secas ou a leste do } \\
\text { Meridiano de } 44^{\circ} \mathrm{W} \text {, do Estado do Maranhão; }\end{array}$ & Cinquenta hectares \\
\hline & Localizada em qualquer outra região do País & Trinta hectares \\
\hline
\end{tabular}

Fonte: Silva, 2014 Com base na Lei ${ }^{\circ}$ 4.771/1965, e alterações pela Lei ${ }^{\circ}$ 7.803/1989, e M.P. $\mathrm{n}^{\circ} 2.166$ 67/2001.

Definições da Lei $n^{0}$ 12.651/2012 
A Lei $n^{\circ}$ 12.727/ 2012 apresenta as novas diretrizes a serem seguidas com relação à utilização do solo, considerando os critérios de ocupação das áreas de preservação permanente e reserva legal, bem como delimita as maneiras de supressão de vegetação, conforme quadro 02.

Quadro 02 - Definiçõos instituídas pela Lei no 12.727 de 2012.

\begin{tabular}{|c|c|c|}
\hline Tipologia & Descrição & Detalhamento \\
\hline \multirow{16}{*}{$\begin{array}{c}\text { Área de } \\
\text { Proteção } \\
\text { Permanente - } \\
\text { APP - Art. } 4^{\circ}\end{array}$} & \multirow{5}{*}{$\begin{array}{l}\text { I - as faixas marginais } \\
\text { de qualquer curso } \\
\text { d'água natural perene e } \\
\text { intermitente, excluídos } \\
\text { os efêmeros, desde a } \\
\text { borda da calha do leito } \\
\text { regular, em largura } \\
\text { mínima de: }\end{array}$} & $\begin{array}{l}\text { a) } 30 \text { (trinta) metros, para os cursos d'água de } \\
\text { menos de } 10 \text { (dez) metros de largura; }\end{array}$ \\
\hline & & $\begin{array}{l}\text { b) } 50 \text { (cinquenta) metros, para os cursos d'água que } \\
\text { tenham de } 10 \text { (dez) a } 50 \text { (cinquenta) metros de } \\
\text { largura; }\end{array}$ \\
\hline & & $\begin{array}{l}\text { c) } 100 \text { (cem) metros, para os cursos d'água que } \\
\text { tenham de } 50 \text { (cinquenta) a } 200 \text { (duzentos) metros } \\
\text { de largura; }\end{array}$ \\
\hline & & $\begin{array}{l}\text { d) } 200 \text { (duzentos) metros, para os cursos d'água } \\
\text { que tenham de } 200 \text { (duzentos) a } 600 \text { (seiscentos) } \\
\text { metros de largura; }\end{array}$ \\
\hline & & $\begin{array}{l}\text { e) } 500 \text { (quinhentos) metros, para os cursos d'água } \\
\text { que tenham largura superior a } 600 \text { (seiscentos) } \\
\text { metros; }\end{array}$ \\
\hline & \multirow{2}{*}{$\begin{array}{l}\text { II - as áreas no entorno } \\
\text { dos lagos e lagoas } \\
\text { naturais, em faixa com } \\
\text { largura mínima de: }\end{array}$} & $\begin{array}{l}\text { a) } 100 \text { (cem) metros, em zonas rurais, exceto para o } \\
\text { corpo d'água com até } 20 \text { (vinte) hectares de } \\
\text { superfície, cuja faixa marginal será de } 50 \\
\text { (cinquenta) metros }\end{array}$ \\
\hline & & b) 30 (trinta) metros, em zonas urbanas \\
\hline & \multicolumn{2}{|c|}{$\begin{array}{l}\text { III - as áreas no entorno dos reservatórios d'água artificiais, decorrentes de } \\
\text { barramento ou represamento de cursos d'água naturais, na faixa definida na } \\
\text { licença ambiental do empreendimento; }\end{array}$} \\
\hline & \multicolumn{2}{|c|}{$\begin{array}{l}\text { IV - as áreas no entorno das nascentes e dos olhos d'água perenes, qualquer } \\
\text { que seja sua situação topográfica, no raio mínimo de } 50 \text { (cinquenta) metros; }\end{array}$} \\
\hline & \multicolumn{2}{|c|}{$\begin{array}{l}\mathrm{V} \text { - as encostas ou partes destas com declividade superior a } 45^{\circ} \text {, equivalente a } \\
100 \% \text { (cem por cento) na linha de maior declive; }\end{array}$} \\
\hline & \multicolumn{2}{|c|}{ VI - as restingas, como fixadoras de dunas ou estabilizadoras de mangues; } \\
\hline & \multicolumn{2}{|c|}{ VII - os manguezais, em toda a sua extensão; } \\
\hline & \multicolumn{2}{|c|}{$\begin{array}{l}\text { VIII - as bordas dos tabuleiros ou chapadas, até a linha de ruptura do relevo, } \\
\text { em faixa nunca inferior a } 100 \text { (cem) metros em projeções horizontais; }\end{array}$} \\
\hline & \multicolumn{2}{|c|}{$\begin{array}{l}\text { IX - no topo de morros, montes, montanhas e serras, com altura mínima de } \\
100 \text { (cem) metros e inclinação média maior que } 25^{\circ} \text {, as áreas delimitadas a } \\
\text { partir da curva de nível correspondente a } 2 / 3 \text { (dois terços) da altura mínima da } \\
\text { elevação sempre em relação à base, sendo esta definida pelo plano horizontal } \\
\text { determinado por planície ou espelho d'água adjacente ou, nos relevos } \\
\text { ondulados, pela cota do ponto de sela mais próximo da elevação; }\end{array}$} \\
\hline & \multicolumn{2}{|c|}{$\begin{array}{l}\text { X - as áreas em altitude superior a } 1.800 \text { (mil e oitocentos) metros, qualquer } \\
\text { que seja a vegetação; }\end{array}$} \\
\hline & \multicolumn{2}{|c|}{ XI - em veredas, a faixa marginal, em projeção horizontal, com largura } \\
\hline
\end{tabular}




\begin{tabular}{|c|c|c|}
\hline & $\begin{array}{l}\text { mínima de } 50 \text { (cinquent } \\
\text { e encharcado. }\end{array}$ & metros, a partir do espaço permanentemente brejoso \\
\hline \multirow{4}{*}{$\begin{array}{l}\text { Reserva legal } \\
-\mathrm{RL}-\text { Art. } 12^{\circ}\end{array}$} & \multirow{3}{*}{$\begin{array}{l}\text { I) localizado na } \\
\text { Amazônia Legal: }\end{array}$} & $\begin{array}{l}\text { a) } 80 \% \text { (oitenta por cento), no imóvel situado em } \\
\text { área de florestas; }\end{array}$ \\
\hline & & $\begin{array}{l}\text { b) } 35 \% \text { (trinta e cinco por cento), no imóvel situado } \\
\text { em área de cerrado; }\end{array}$ \\
\hline & & $\begin{array}{l}\text { c) } 20 \% \text { (vinte por cento), no imóvel situado em área } \\
\text { de campos gerais; }\end{array}$ \\
\hline & $\begin{array}{l}\text { II - localizado nas } \\
\text { demais regiões do País: }\end{array}$ & $20 \%$ (vinte por cento). \\
\hline $\begin{array}{c}\text { Cadastro } \\
\text { Ambiental } \\
\text { Rural }- \text { CAR } \\
\text { Art. } 29^{\circ} \\
\end{array}$ & \multicolumn{2}{|c|}{$\begin{array}{l}\S 3^{0} \text { A inscrição no CAR será obrigatória para todas as propriedades e posses } \\
\text { rurais, devendo ser requerida no prazo de } 1 \text { (um) ano contado da sua } \\
\text { implantação, prorrogável, uma única vez, por igual período por ato do Chefe } \\
\text { do Poder Executivo. }\end{array}$} \\
\hline $\begin{array}{c}\text { Programa de } \\
\text { Regularização } \\
\text { Ambiental - } \\
\text { PRA } \\
\text { Art. 59 }\end{array}$ & \multicolumn{2}{|c|}{$\begin{array}{l}\text { Os compromissos de manter, recuperar ou recompor as áreas de preservação } \\
\text { permanente, de reserva legal e de uso restrito do imóvel rural, ou ainda de } \\
\text { compensar áreas de reserva legal; }\end{array}$} \\
\hline
\end{tabular}

\section{RESULTADOS E DISCUSSÕES}

A alteração do Código Florestal, amplamente comentada e divulgada, repercutiu em diversas esferas de conhecimentos, e ainda apresenta muitas divergências de entendimentos.

Os principais pontos de discussão e debates acerca das alterações em áreas de bacia hidrográfica estabelecidas pela Lei n 9.433/1997, são: delimitação das áreas de preservação permanente, reserva legal, cadastro ambiental rural.

\section{Discussão: Área de Preservação Permanente}

A edição da legislação florestal apresenta uma readequação dos limites de preservação ambiental, considerando o uso atual das áreas e principalmente possibilitando a real manutenção dessas áreas de proteção. 


\section{Revista Tecnologia e Ambiente, v. 22, 2016, Criciúma, Santa Catarina}

ISSN 1413-8131

Analisando a situação atual das APP e a falta de técnicos habilitados para aplicação da Lei em período integral, em muitos locais é possível observar o descumprimento da mesma.

As reduções das áreas de preservação não contribuem para uma degradação, e sim, possibilitam de forma amena a recomposição de áreas anteriormente degradadas.

Para uma efetividade maior da legislação nacional seria necessária a realização de um mapeamento da situação florestal do país, considerando a extensão territorial e a divergência de ecossistemas existentes, as particularidades e generalidades que são encontradas em muitas situações podem dificultar o processo de aplicação da norma regulamentadora.

A nova lei, definiu que áreas de preservação já alteradas e em uso anterior a julho de 2008, seriam consideradas áreas consolidadas e abriu precedentes para recomposição de mata ciliar com tamanhos inferiores aos valores apresentados no art. $4^{\circ}$, definindo medida inicial em 5 metros para terrenos com até 1 módulo fiscal, e o tamanho deste módulo varia de acordo com cada município.

\section{Discussão: Reserva Legal}

Considerando a necessidade de proteção ambiental em áreas onde não existe a possibilidade de definição de área de preservação permanente (APP), a reserva legal é instituída como ferramenta para a proteção florestal.

A área de reserva legal é estabelecida de acordo com a caracterização do bioma, e o tamanho da propriedade rural. A redação dada pela Lei $\mathrm{n}^{\circ} 12.727 / 2012$, que altera parte da Lei $\mathrm{n}^{\circ} 12.651 / 2012$, referente a reserva legal já estava em vigor na forma de medida provisória criada em 2001, não causando prejuízos as áreas de preservação permanente.

\section{Discussão Cadastro Ambiental Rural}

A nova legislação florestal institui a criação de um cadastro ambiental rural (CAR), com o objetivo de acompanhar o desenvolvimento das atividades rurais e fortalecer os procedimentos de monitoramento e controle ambiental. 
O sistema implantado é considerado válido, observando a possibilidade de acompanhamento das ações ambientais a nível nacional sem a necessidade de verificação in loco de todas as áreas passíveis de licenciamentos específicos, devido a um sistema online criado para autodeclaração, possibilitando deste modo, agilidade nos procedimentos e maior garantia de preservação ambiental.

Juntamente com o cadastro ambiental, foram criados programas de regularização ambiental (PRA), que tem como objetivo auxiliar na manutenção, recuperação e/ou recomposição das áreas de preservação permanente, de reserva legal e de uso restrito do imóvel rural, ou ainda de compensar áreas de reserva legal.

Os dados apresentados acima foram relacionados de acordo com as principais dúvidas existentes com relação às alterações do Código Florestal na bacia hidrográfica do rio Araranguá.

Outros artigos, além dos mencionados, sofreram alterações, sendo suprimidos ou atualizados na nova versão, bem como a inserção de novos artigos, considerados importantes para a atual fase de sensibilização das pessoas para a proteção do meio ambiente, sendo por vontade própria ou por força da aplicação da Lei.

\section{Verificação da aplicação prática e o impacto das novas regras no âmbito da Bacia Hidrográfica do Rio Araranguá}

A Bacia Hidrográfica do Rio Araranguá está localizada na porção do Extremo Sul Catarinense, conforme Figura 1. A aplicabilidade da lei em áreas de bacias hidrográficas é relacionada geralmente ao processo de fiscalização, considerando que a aplicação das leis no Brasil é baseada em penalidades, deste modo, é necessário fortalecer setores ambientais até então sucateados devido à falta de interesse do desenvolvimento destes setores pelos gestores públicos.

$\mathrm{Na}$ área da bacia hidrográfica do Rio Araranguá, também se visualiza os procedimentos de aplicação de lei devido às exigências legais, embora de forma singular seja possível visualizar um movimento de mobilização dos atores sociais em busca de qualidade e quantidade de água suficiente para desenvolvimento de suas atividades. Neste sentido, os produtores estão sendo sensibilizados a realizar procedimentos ambientais de preservação da mata ciliar e vegetação nativa, pensando 
na manutenção dos mananciais naturais e ainda na capacidade da vegetação de reter a água.

Figura 1 - Localização da Bacia Hidrográfica do Rio Araranguá

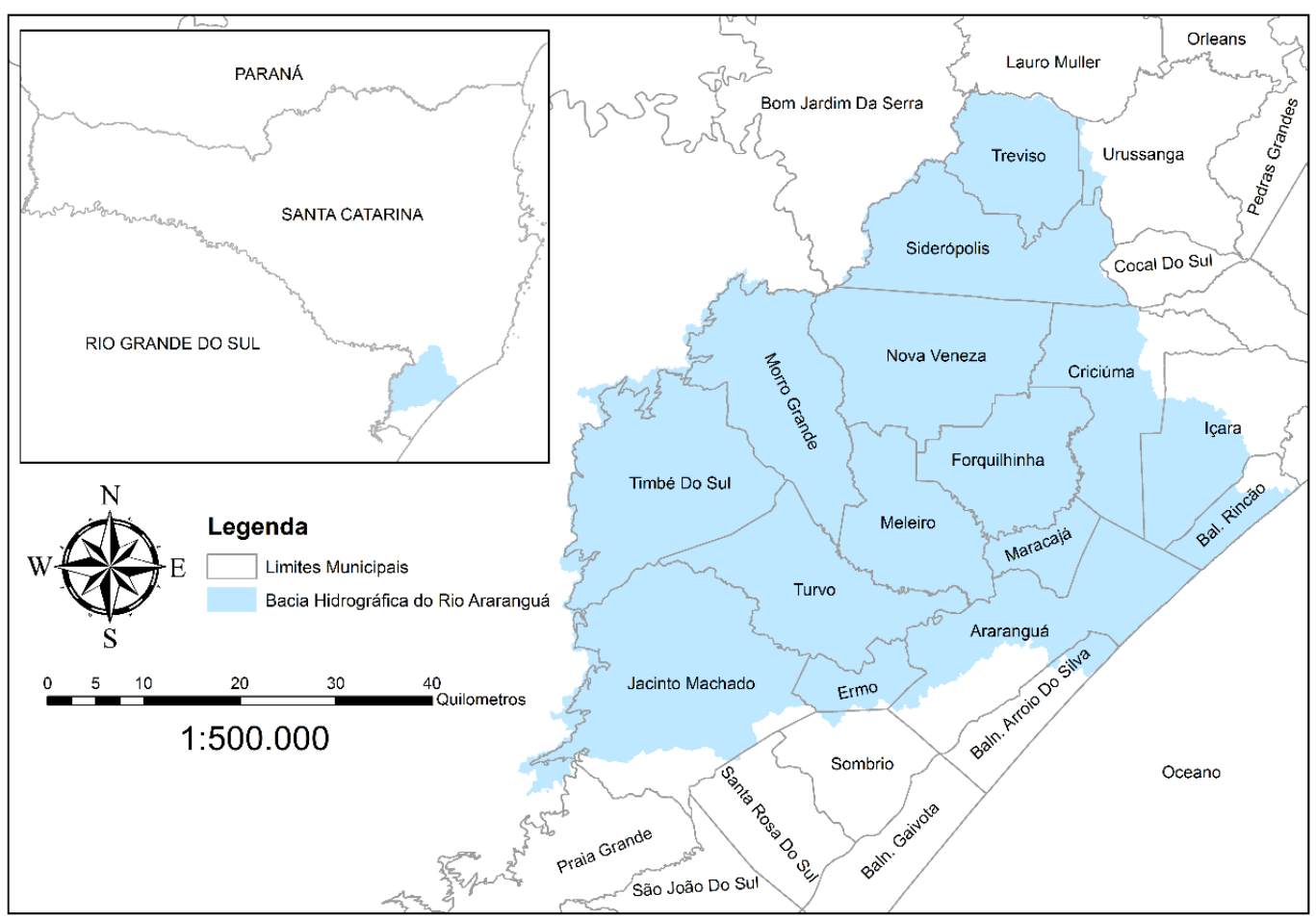

Fonte: Localização da Bacia Hidrográfica do Rio Araranguá. Fiegenbaum (2016).

Outro importante ponto a ser relacionado ao novo código ambiental e à "consciência" da população é a possibilidade de desenvolvimento de atividades que possam gerar bônus financeiro, denominado de pagamento por serviços ambientais prestados. Essa consciência dos produtores vem sendo estimulada por diversos setores da economia, facilitando o processo de preservação e proteção dos recursos naturais.

O novo código florestal, na bacia do Araranguá, foi visto como benéfico para a agricultura familiar, visto que possibilita a utilização da área de reserva legal, em propriedades com menos de 4 módulos fiscais. Sendo que nesta bacia, boa parte de sua economia é proveniente da agricultura familiar.

\section{CONCLUSÃO}


O desenvolvimento da pesquisa acerca das alterações do Código Florestal possibilita, de forma clara e objetiva, a resolução de questionamentos referentes a possíveis medidas a serem tomadas com base na nova lei, sendo que as discussões iniciais sobre a possível alteração do Código causaram extremo alvoroço na comunidade científica, bem como entre leigos, em busca de informações pertinentes relacionadas às alterações e quais seriam as novas determinações a serem seguidas.

Embora a discussão inicial do Código Florestal tenha alarmado a sociedade, com as diversas emendas e resoluções para suprir falhas na nova versão colocada em discussão em 2012, foram definidas medidas que possibilitam o desenvolvimento das atividades de maneira a se obter um equilíbrio entre o desenvolvimento das atividades econômicas e o ganho ambiental com a recomposição de vegetação até então desconsiderada.

O Comitê de Bacia Hidrográfica do Rio Araranguá é um importante colegiado de articulação de atores sociais e possibilita disseminar informações que anteriormente não foram apresentadas, permitindo o acesso à informação de pessoas sem conhecimento técnico necessário para compreender os termos empregados.

As alterações no Código Florestal apresentam diferentes pontos a serem observados e seguidos. Sendo que as principais discussões são acerca do estabelecimento de reserva legal em proporções diferentes das anteriores, reduzindo áreas e possibilitando que produtores familiares tenham suas terras legalizadas. Áreas de preservação permanente também obtiveram destaque nos amplos debates, considerando a possibilidade de computar a Reserva Legal em área de APP, favorecendo os pequenos produtores rurais.

As mudanças ocasionadas pela nova Lei possuem impactos significativos, quando aplicados de forma prática e com a devida fiscalização, porém é importante ressaltar que o sistema ambiental nacional apresenta falhas no desenvolvimento dos processos de fiscalização, levando em considerando a ausência de técnicos habilitados para tal atividade. Esta fragilidade é o principal gargalo no avanço à proteção dos recursos naturais.

A estruturação dos comitês de bacias, e a elaboração do Plano de Gerenciamento de Bacia Hidrográfica, permitem a aplicação da Lei de proteção das florestas a lei de proteção dos recursos hídricos, considerando que o processo de outorga e cobrança de 
água são instrumentos de gestão de recursos hídricos, que definem a aplicação do recurso na própria bacia, ampliando o desenvolvimento de atividades sustentáveis e de proteção dos recursos naturais. As Leis do Código Florestal e Plano Nacional de Recursos Hídricos são indiretamente interligadas em seus objetivos gerais, visto que a proteção dos recursos hídricos está diretamente ligada ao uso e conservação do solo.

A aplicação prática da legislação federal, em qualquer instância instancia precisaria inicialmente ser desenvolvida de forma participativa com a sociedade, para que esta possa incorporar os procedimentos que serão exigidos em seu dia a dia, e a necessidade de aplicação das leis de forma correta.

A comunidade da bacia do rio Araranguá, bem como de todo território nacional, precisa ser sensibilizada sobre a importância da preservação dos recursos naturais, e não apenas sofrer as consequências de duras multas ambientais, que resolvem os problemas de forma ineficiente, devido a pequenos setores arcarem com multas e apresentarem dificuldades em desenvolver suas atividades, e os grandes setores incorporam as multas a seus projetos e não realizam os processos de recuperação necessários.

Acusando a falta de consciência ambiental e a ausência de processos de sensibilização, é necessário relacionar a força dos gestores públicos a ações práticas da comunidade de forma a se desenvolver ações ambientais para que se tenha efetivamente a proteção dos recursos naturais conforme determina a lei.

Deste modo, o Brasil avança em seu desenvolvimento com o planejamento e o fortalecimento de sua legislação após aprovação da nova redação do Código Florestal, que implica em novos procedimentos para as atividades e a busca pelo desenvolvimento sustentável.

\section{REFERÊNCIAS}

ADAMI, R. M.; CUNHA, Y. M.; FRANK, B. Caderno do educador ambiental das bacias dos rios Araranguá e Urussanga. Blumenau, SC: Fundação Agência de Água do Vale do Itajaí, 2010. P. 28-31.

BRASIL. Constituição (1988). Constituição da República Federativa do Brasil. Brasília, DF: Senado Federal, 1988.

Decreto $\mathbf{n}^{\mathbf{0}} \mathbf{7 . 8 3 0}$, de 17 de outubro de 2012. Sistema Cadastro Ambiental

Rural. Disponível em: <http://www.planalto.gov.br/CCIVIL_03/_Ato20112014/2012/Decreto/D7830.htm>. Acesso em: out. 2013. 
- Decreto $\mathrm{n}^{\mathbf{0}}$ 6.514, de 22 de julho de 2008. Infrações e sanções <http://www.planalto.gov.br/ccivil_03/_ato2007-2010/2008/decreto/d6514.htm>.

Acesso em: out. 2016.

Lei 9.433 de 08 de janeiro de 1997. Política Nacional de Recursos Hídricos. Disponível em: <http://www.planalto.gov.br/ccivil_03/Leis/L9433.htm>. Acesso em: out. 2013.

Lei $N^{0}$ 12.651, de 25 de maio de 2012. Proteção da vegetação nativa. Disponível em: <http://www.planalto.gov.br/ccivil_03/_Ato20112014/2012/Lei/L12651.htm>. Acesso em: out. 2013.

Lei $\mathbf{N}^{\mathbf{0}}$ 12.727, de 17 de outubro de 2012. ALTERA A LEI N $\mathrm{N}^{\mathrm{O}} 12.651$. Disponível em: <http://www.planalto.gov.br/ccivil_03/_Ato20112014/2012/Lei/L12727.htm>. Acesso em: out. 2013.

Lei 4.771, de 15 de setembro de 1965. Código Florestal. Disponível em: <http://www.planalto.gov.br/ccivil_03/leis/14771.htm>. Acesso em: out. 2013.

Lei $n^{\circ}$ 9.605, de 12 de fevereiro de 1998. Sanções penais e administrativas derivadas de condutas e atividades lesivas ao meio ambiente. Disponível em: < http://www.planalto.gov.br/ccivil_03/leis/L9605.htm>. Acesso em: out. 2016.

CARVALHO, Edson Ferreira. Código Florestal, relative verfassungswidrigkeit "and" die unterschiedlichkeit der regelung: o tiro pode sair pela culatra. Revista de Direito Ambiental, São Paulo, v. 19, n. 75 , p.261-288,, set. 2014.

COMISSÃO MUNDIAL ENTRE MEIO AMBIENTE E DESENVOLVIMENTO. Relatório Brundtland: Nosso futuro comum. 2. ed. Rio de Janeiro: Editora Fundação Getúlio Vargas. 1991. Disponível em: <http://pt.scribd.com/doc/12906958/RelatorioBrundtland-Nosso-Futuro-Comum-Em-Portugues>. Acesso em: out. 2013.

FIEGENBAUM. Ives. Localização da Bacia Hidrográfica do Rio Araranguá. Criciúma. Do Autor. Elaborado em Arcgis. 2016. 1 Mapa.

IBGE, Censo Demográfico 2010. Disponível em: <http://www.ibge.gov.br>. Acesso em: jan. de 2014.

KRINSKI. S. Código Florestal: novo marco regulatório. Disponível em: http://negociosdaterra.com.br/2012/10/19/codigo-florestal-novo-marco-regulatorio-porsilvio-krinski/ Acesso em out. 2013.

KRINSKI. S. Treinamento Código Florestal. Disponível em: $<$ http://prezi.com/o1zmh5rhqrtv/treinamento-codigo-

florestal/?utm_source=website\&utm_medium=prezi_landing_related\&utm_campaign= prezi_landing_related_author>. Acesso em: out. 2013.

MAGAlHÃES, J. P. Comentário ao Código Florestal: doutrina e jurisprudência. 2. ed. São Paulo, Ed. Juarez de Oliveira. 2001.

MENDONÇA, F.; SANTOS, L. J. C. Gestão da água e dos recursos hídricos no Brasil: avanços e desafios a partir das bacias hidrográficas - uma abordagem geográfica. Geografia (Rio Claro), Rio Claro, SP, v.31, n.1, p. 103-117, abr. 2006. 
MILARÉ. E. Direito do Ambiente. $8^{\text {a }}$ ed. Ver, atual. E ampl. - São Paulo. Editora Revista dos Tribunais, 2013.

PHILIPPI JUNIOR, Arlindo (Org.) Métodos e técnicas de pesquisa em Educação Ambiental. In: Saneamento, saúde e ambiente: fundamentos para um desenvolvimento sustentável. Barueri, SP: Manole, 2005. p. 584 - 596.

PHILIPPI JUNIOR, Arlindo (Org.). Pesquisa Social: métodos aplicados ao saneamento. Saneamento, saúde e ambiente: fundamentos para um desenvolvimento sustentável. Barueri, SP: Manole, 2005. p. $601-615$.

RODRIGUES, Marcelo Abelha. Áreas consolidadas no Código Florestal (Lei 12.651/2012): uma vergonha sem precedentes no direito ambiental brasileiro. Revista de Direito Ambiental, São Paulo, v. 18, n. 69 , p.345-356, mar. 2013.

SANTA CATARINA. Plano de Recursos Hídricos da Bacia do Rio Araranguá. Santa Catarina. 2015. 5v.

SILVA. M.P. A Reforma do Código Florestal e Aplicação Prática das Novas Regras no Âmbito da Bacia Hidrográfica do Rio Araranguá - SC. 2014. 43 fls. TCC (Curso Pós Graduação em Direito Ambiental) Universidade Federal do Paraná, Curitiba - PR, 2014.

SPAROVEK, G. A revisão do Código Florestal Brasileiro. Novos Estudos CEBRAP, São Paulo, n. 89, p.111-135, mar. 2011. 